\title{
Loss of Nkx3.1 Expression in Bacterial Prostatitis
}

\section{A Potential Link Between Inflammation and Neoplasia}

\author{
May Khalili, ${ }^{*}$ Laura N. Mutton, ${ }^{*}$ Bora Gurel, ${ }^{\dagger}$ \\ Jessica L. Hicks, ${ }^{\dagger}$ Angelo M. De Marzo, ${ }^{\dagger}$ \\ and Charles J. Bieberich ${ }^{\star \ddagger}$ \\ From the Department of Biological Sciences,* University of \\ Maryland Baltimore County, Baltimore; the Department of \\ Pathology, Division of Genitourinary Pathology, Johns Hopkins \\ University, Baltimore; and the University of Maryland Marlene \\ and Stewart Greenbaum Cancer Center, ${ }^{\ddagger}$ Baltimore, Maryland
}

NKX3.1 is a homeodomain protein that functions as a dosage sensitive prostate-specific transcription factor. Diminished NKX3.1 expression is associated with prostate epithelial cell proliferation in vitro and with increasing Gleason grade in patient samples. Mouse Nkx3.1 also functions as a negative regulator of prostate cell growth in prostate cancer models. Identifying biological and environmental factors that modulate NKX3.1 accumulation is therefore central to efforts aimed at elucidating prostate growth control mechanisms. To determine the effect of inflammation on Nxk3.1 accumulation, bacterial prostatitis was induced by intraurethral inoculation of a uropathogenic $E$. coli strain in mice. Nkx3.1 expression was profoundly reduced in infected prostate lobes and correlated with increased expression of a proliferation marker. Androgen receptor levels were also reduced in concert with $N k x 3.1$, and a marked increase in the basal cell marker p63 was observed. Analyses of the inflammatory infiltrate revealed a classic acute inflammatory response that attained characteristics of a chronic state within fourteen days postinoculation. Comparison of the four prostate lobes revealed clear differences in the extent of inflammation. These data demonstrate that acute inflammation in response to a bacterial agent in the prostate is associated with a significant diminution in the level of a key regulator of prostate cell proliferation. These observations provide a plausible mechanism whereby prostate inflammation may establish a local environment conducive to epithelial cell growth. (Am J Pathol 2010, 176:2259-2268; DOI: 10.2353/ajpath.2010.080747)
Prostate cancer ranks after lung cancer as the secondleading cause of cancer death among men in the United States. ${ }^{1}$ Although the molecular basis of prostate carcinogenesis remains unclear, a multiplicity of factors, including aging, diet, environmental factors, and genetic susceptibility affect overall risk. ${ }^{2,3}$ In the human prostate, cancer occurs most commonly in the peripheral zone and is a progressive and multistep disease. ${ }^{4,5}$ As with other epithelial cancers, the accumulation of genetic alterations that affect cell proliferation, survival, and apoptosis is thought to underlie prostate carcinogenesis. ${ }^{6-8}$

Chronic inflammation over a prolonged period has been correlated with the emergence of cancer in several organs. ${ }^{9-11}$ Recently, a hypothesis has been proposed linking prostate carcinogenesis to chronic inflammation and areas of atrophic/regenerative epithelium. ${ }^{3}$ Atrophic lesions are often associated with signs of ongoing chronic inflammation in the prostate. ${ }^{12}$ Focal atrophy is frequently encountered in the prostate and has been documented for more than half a century. ${ }^{13}$ Although atrophic in appearance, epithelial cells within the lesions have a high proliferative and low apoptotic index, leading to the term proliferative inflammatory atrophy (PIA). ${ }^{14}$ The frequent occurrence of atrophic lesions in close proximity to, and sometimes merging with, areas of prostatic intraepithelial neoplasia (PIN) suggests that PIA may represent a potential precursor of prostate cancer. Furthermore, along with increases in proliferation markers, and similar to high-grade PIN and carcinoma lesions, luminal cells in PIA lesions showed a decrease in expression of

Supported by Congressionally Directed Medical Research Program grant DAMD-03-1-0091 (to C.J.B.). A.M.D. is the Beth W. and A. Ross Myers Scholar in which he and C.J.B. are supported through the Patrick C. Walsh Prostate Cancer Research Fund.

Accepted for publication December 24, 2009.

Supplemental material for this article can be found on http://ajp. amjpathol.org

Address reprint requests to Charles J. Bieberich, Ph.D., Department of Biological Sciences, University of Maryland Baltimore County, 1000 Hilltop Circle, Baltimore, MD 21250. E-mail: bieberic@umbc.edu. 
p27Kip1/CDKN1B, a haploinsufficient tumor suppressor and cyclin-dependent kinase inhibitor, and an increase in C-MYC protein. ${ }^{14-16}$

Although the prostate is a frequent site of inflammation and the coincidence of lymphocytic infiltration and either precursor lesions or overt adenocarcinoma is common, a causal relationship between these entities has not been established. In most cases of the subset of clinical prostatitis that are associated with inflammation in prostatic fluid, the cause of inflammation is unclear. Nevertheless, a variety of pathogenic organisms are known to infect the prostate and give rise to an inflammatory response. ${ }^{3}$ In the majority of acute and chronic bacterial prostatitis cases, Gram-negative organisms, for example, Escherichia coli, are implicated. ${ }^{17}$ Recently, a mouse model of bacterial prostatitis was developed. In this system, $\mathrm{C} 3 \mathrm{H} /$ HeOuJ mice developed acute prostatic inflammation followed by a persistent inflammatory response after intraurethral inoculation with a uropathogenic E. coli strain. ${ }^{18}$ Histological analyses revealed reactive epithelial hyperplasia associated with oxidative stress in infected mice. The availability of a bacterial prostatitis model in an organism where prostate growth and development have been well characterized and genetic manipulations are possible can facilitate mechanistic analyses of these associations.

The main objective of the current study was to explore a potential mechanistic link between a key prostate growth control regulator and prostate inflammation. The central focus was on Nkx3.1, a homeodomain transcription factor that functions as a prostate-specific tumor suppressor. Nkx3.1 is the earliest known marker of prostate development, and its expression remains restricted throughout adulthood to epithelial cells in the prostate. ${ }^{19,20}$ In mice, loss of Nkx3.1 function results in epithelial hyperplasia and dysplasia that worsens with age. ${ }^{21-23}$ In humans, NKX3.1 protein expression is diminished in human prostate cancer, and the loss of NKX3.1 correlates with disease progression. ${ }^{24-26}$ In Nkx3.1 mutant mice, Nkx3.1 loss-of-function leads to deregulated expression of antioxidant and prooxidant enzymes including Prdx6, Qscn6, GPx2, and GPx3. ${ }^{27}$ As a result, it was hypothesized that diminished Nkx3.1 levels might lead to an accumulation of reactive oxygen species, which in turn increases oxidative DNA damage, and ultimately promotes neoplastic transformation. Indeed, PIA lesions are reported to exhibit reduced NKX3.1 expression, which may contribute to increased oxidant damage. ${ }^{28}$

Using a mouse model of bacterial prostatitis, we performed immunohistochemical analysis to investigate Nkx3.1 protein levels in inflamed prostates. Detailed histological analyses of the four prostate lobes revealed profound alterations in Nkx3.1 levels. Given the wellestablished role of Nkx3.1 in controlling prostate growth and in protecting cells from oxidative stress, our observations of diminished $\mathrm{Nk} \times 3.1$ accumulation provide a potential mechanistic link between inflammation carcinogenesis risk in prostate epithelial cells.

\section{Materials and Methods}

\section{Bacterial Strain and Growth Conditions}

Uropathogenic E. coli strain CP9 was a kind gift from Dr. A.D. O'Brien (Uniformed Services University of the Health Sciences, Bethesda, MD). This strain is a human blood isolate that expresses cytotoxic necrotizing factor 1 and Hemolysin ${ }^{29}$ and has previously been reported to be virulent in a number of in vitro and in vivo models. ${ }^{29-32}$ The E. coli CP9 inoculum used to infect mice was prepared by inoculating a single colony into $5 \mathrm{ml}$ of static Luria Broth for 16 hours followed by passage into $50 \mathrm{ml}$ of static Luria Broth for 48 hours at $37^{\circ} \mathrm{C}$. Bacteria were then adjusted to an $A_{600}$ of 0.85 and $6 \mathrm{ml}$ were pelleted by centrifugation at $10,000 \mathrm{~g}$ for 5 minutes at $4^{\circ} \mathrm{C}$. After centrifugation the pellet was resuspended in $2 \mathrm{ml}$ of sterile saline to give a bacterial density of $2.5 \times 10^{8} \mathrm{CFU} / \mathrm{ml}$.

\section{Animals and Intraurethral Inoculation}

Male $\mathrm{C} 3 \mathrm{H} / \mathrm{HeOuJ}$ mice were obtained from the Jackson Laboratory (Bar Harbor, ME) and were housed in an animal biosafety level 2 barrier facility (Spring Valley Laboratories, Woodbine, MD). All animal procedures were approved by the University of Maryland Baltimore County Institutional Animal Care and Use Committee. Under anesthesia (avertin, $250 \mathrm{mg} / \mathrm{kg}$ I.P.), mice were catheterized using sterile polyethylene tubing (PE-10, Intramedic, Becton Dickinson, Sparks, MD), and $100 \mu \mathrm{l}$ of the inoculum was delivered over a 30-second period. Control animals received an equal volume of sterile phosphate buffered saline (PBS). Animals were allowed access to food and water ad libitum.

\section{Tissue Harvesting and Processing}

Mice were euthanized 5, 10, and 14 days after inoculation by $\mathrm{CO}_{2}$ asphyxiation followed by cervical dislocation. The prostate gland, bladder, urethra, and seminal vesicles were dissected and fixed in $4 \%$ paraformaldehyde for 4 hours. Tissue specimens were transferred to $70 \%$ ethanol and processed for standard paraffin embedding. Paraffin blocks were sectioned at five-micron intervals, and sections were mounted on Superfrost/Plus microscopic slides (Fisherbrand, Fisher Scientific, Chicago, IL). Standard hematoxylin and eosin (H\&E) staining was performed for histological analyses.

\section{Immunohistochemistry}

Tissue sections were deparrafinized, rehydrated and briefly equilibrated in water. For Nk×3.1 and androgen receptor (AR) immunohistochemistry, antigen unmasking was performed by boiling slides in $1 \mathrm{mmol} / \mathrm{L}$ EDTA ( $\mathrm{pH}$ 8.0) for 15 minutes. For p63 staining, slides were steamed for 20 minutes in Antigen Unmasking Solution (Vector Laboratories, Burlingame CA) for 20 minutes. For $\mathrm{Ki}-67, \mathrm{CD} 3$, and F4/80 staining, slides were steamed in High Temperature Target Retrieval Solution (Dako Cyto- 
mation, Carpentaria, CA) for 40 minutes. Endogenous peroxidase activity was quenched by incubation with peroxidase block for 5 minutes at room temperature. For Nkx3.1 and AR staining, nonspecific binding was blocked by incubating in $1 \%$ bovine serum albumin in Tris- $\mathrm{HCl}$ pH 7.5 for 20 minutes at room temperature. Slides were incubated with primary antibodies including a rabbit polyclonal anti-mouse Nkx3.1 antibody ${ }^{33}$ (1:2000 dilution) for 1 hour at room temperature; rabbit polyclonal anti-mouse AR antibody (Upstate Biotechnology, Lake Placid, NY; 1:750 dilution) for 1.5 hours at room temperature; mouse monoclonal anti-mouse p63 (Labvision Neomarkers, Freemont, CA; 1:50 dilution) for 45 minutes at room temperature; rabbit polyclonal anti-human CD3 antibody (Dako Cytomation, Carpinteria, CA; 1:1000 dilution) overnight at $4^{\circ} \mathrm{C}$; rabbit polyclonal $\mathrm{Ki}-67$ antibody (Novocastra, Burlingame, CA; 1:1200 dilution) for 45 minutes at room temperature; rat monoclonal anti-mouse F4/80 antibody (Serotec Inc, Raleigh, NC; 1:10000 dilution) for 45 minutes at room temperature. After F4/80 primary antibody application, slides were incubated with a rabbit anti-rat IgG antibody (Dako Cytomation, Carpinteria, CA) at 1:3000 dilution for 30 minutes at room temperature. A horseradish peroxidase-labeled polymer (Dako Cytomation, Carpentaria, CA) was applied on all slides for 30 minutes at room temperature. Signal detection was performed using 3,3'-diaminobenzidine tetrahydrochloride (DAB) as the chromagen. Slides were counterstained with hematoxylin, dehydrated, and mounted.

\section{Histopathological Scoring of Prostate Inflammation}

For each prostate lobe, inflammation grade and extent, in percent area affected, for acute and chronic inflammation in luminal, intraepithelial, and stromal compartments were assessed visually. A weighted inflammation score was generated using the following formula: [(Grade 3 percentage $\times 3)+($ Grade 2 percentage $\times 2)+$ Grade 1 percentage]. The inflammation score of each compartment in each lobe were combined to derive a total acute and chronic inflammation score for each lobe, and these scores were summed to derive a total acute and chronic inflammation score for each prostate.

\section{Results}

\section{Histological Features of CP9-Induced Bacterial Prostatitis}

A group of $28 \mathrm{C} 3 \mathrm{H} / \mathrm{HeOuJ}$ males was anesthetized and intraurethrally inoculated with $2.5 \times 10^{7}$ uropathogenic $E$. coli CP9, and 10 control animals were inoculated in parallel with PBS. CP9 was originally isolated from the blood of a patient with pyelonephritis. ${ }^{29}$ Previous studies have shown that this strain is positive for cytotoxic necrotizing factor 1 (CNF1), which confers a selective net growth advantage in lower urinary tract infections. ${ }^{34}$ More than $60 \%$ of patients that present with bacterial prostatitis are infected with CNF1-positive E. coli strains. ${ }^{35,36}$ Groups of mice were euthanized 5,10 , and 14 days postinoculation, and a partial urogenital system including the prostate, seminal vesicles, urethra, and bladder was removed en bloc for histological analyses. The gross morphology of PBS-inoculated control mice appeared normal at all time points. In contrast, CP9-infected mice had slightly enlarged seminal vesicles and prostates by day 5. By day 10 , the overall size of the prostate and seminal vesicles appeared to return to normal. However, by day 14, the prostate and seminal vesicles from CP9-infected mice were opaque and were reduced to less than half the size of PBS-inoculated control prostate and seminal vesicles (data not shown).

\section{Anterior Prostate}

The anterior prostate exhibited variable degrees of inflammation among CP9-infected animals. In some cases, neither lobe was infected, however in other cases one lobe appeared inflamed while the other lobe showed no signs of infection. Furthermore, a mix of inflamed and noninflamed ducts was often seen concomitantly in one lobe. Not unexpectedly the onset of the inflammatory reaction consisted of acute inflammatory cells (primarily neutrophils), and over time there was a progressive increase in the amount of chronic inflammatory cells (mononuclear cells consisting primarily of lymphocytes and macrophages, see below). At day 5 , neutrophils predominated and these were localized primarily in the stroma (Figure 1A). By day 10, apparently infected anterior ducts appeared heavily infiltrated with luminal neutrophils and had lost their characteristic papillary infoldings (Figure 1B). The ductal epithelium had become multilayered with evidence of a moderate degree of apoptosis and scant cytoplasm. Although most ducts remained well circumscribed by the stroma, in more distended ducts, the epithelium was markedly diminished with a complete loss of ductal architecture and with focal evidence of ductal contents spilling into the stroma. In some regions of severe inflammation, squamous metaplasia was observed within the epithelial layer. The epithelial cells within recovering ducts appeared markedly hyperchromatic and piled up, with evidence of cribriform architecture consistent with inflammatory injury and regeneration. The stroma exhibited marked fibrosis with moderate to severe mononuclear inflammatory cell infiltration. By day 14, although most ducts remained inflamed, some ducts had begun to clear the acute inflammatory infiltrate and debris (Figure 1C). At day 14, the anterior prostate exhibited a markedly sclerotic stroma with pockets of severe inflammatory infiltrate and abundant plasma cells. Marked stromal angiogenesis evidenced by an increased number of newly formed capillaries was also observed. There was an increased proportion of ductal spaces that had cleared the inflammatory infiltrate (Figure 1C). The ducts were enclosed by a thickened fibromuscular sheath, and once again the epithelium exhibited cribriform architecture that may indicate regenerating ductal structure. Ducts that remained inflamed had severe glandular infiltration that was mostly 

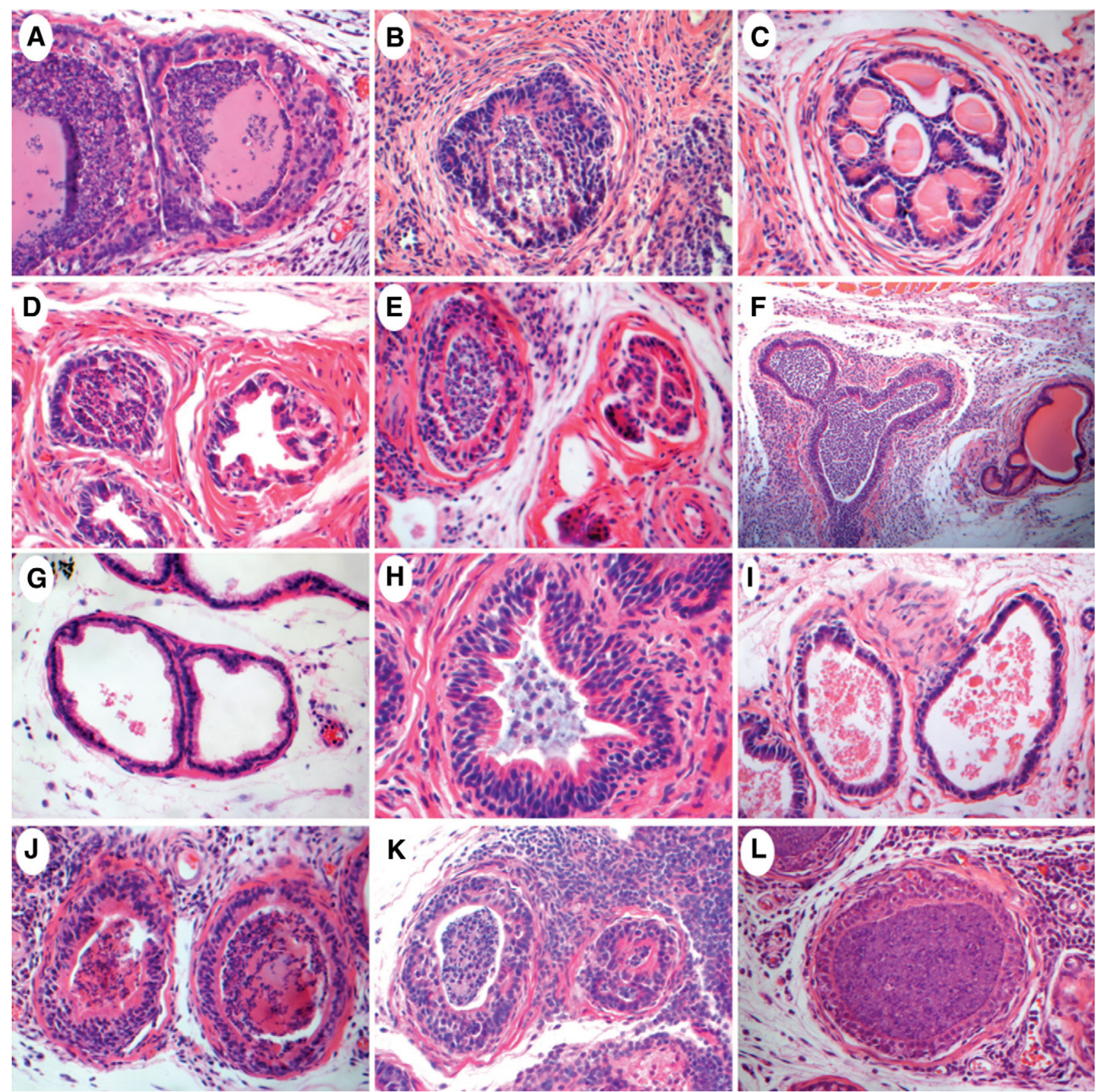

Figure 1. Histopathological analysis of individual prostate lobes from CP9-infected mice at five, 10, and 14 days postinoculation. A-C: Anterior prostate (AP). A: Day five AP showing heavily infiltrated glandular lumen and a multilayered ductal epithelium. Note the complete loss of papillary infoldings within the ductal epithelium. B: Day 10 AP exhibiting hyperchromatic and multilayered epithelium. Note the marked fibrosis within the stromal layer. C: Day 14 AP with a thickened fibromuscular sheath surrounding a recovered duct. Note the newly generated cribriform architecture. D-F: Dorsal prostate (DP). Note the juxtaposition of inflamed and noninflamed ducts in all three panels. D: Day five DP. E: Day 10 DP with a slightly disorganized multilayered epithelium. F: Day 14 DP exhibiting severe glandular and periglandular inflammation. Note the distended duct and hyperchromatic nuclear appearance. G-I: Lateral prostate (LP). G: Day five LP with no apparent inflammation. A few mononuclear inflammatory cells appear in stroma and around the blood capillary. H: Day 10 LP exhibiting an involved duct with mild glandular infiltrate and extensive epithelial multilayering. Note the markedly thickened stromal layer. I: Day 14 LP. Note the slightly thickened stroma and the scattered inflammatory infiltrate in the absence of any apparent glandular inflammation. J-L: Ventral prostate (VP). J: Day five VP. K: Day 10 VP exhibiting dense periglandular infiltrate with disorganized and multilayered ductal epithelia. L: Day 14 VP. Note the increase in newly formed stromal capillaries. Original magnifications: $\times 400(\mathbf{A}-\mathbf{E}, \mathbf{G}-\mathbf{L}) ; \times 100(\mathbf{F})$. H\&E staining.

neutrophilic. The epithelium was multilayered, disorganized, and exhibited signs of reactive nuclear atypia.

\section{Dorsal Prostate}

Similar to the anterior prostate, the dorsal prostate contained a mix of involved and uninvolved lobes. In addi- tion, the juxtaposition of inflamed and noninflamed ducts within the same lobe was frequently encountered. At day 5 , inflamed ducts exhibited severe neutrophil luminal infiltration (Figure 1D) that was present in all three main compartments (intralumial, stromal, and intraepithelial). The ductal epithelium appeared hyperchromatic and multilayered at times with a complete loss of infoldings. 


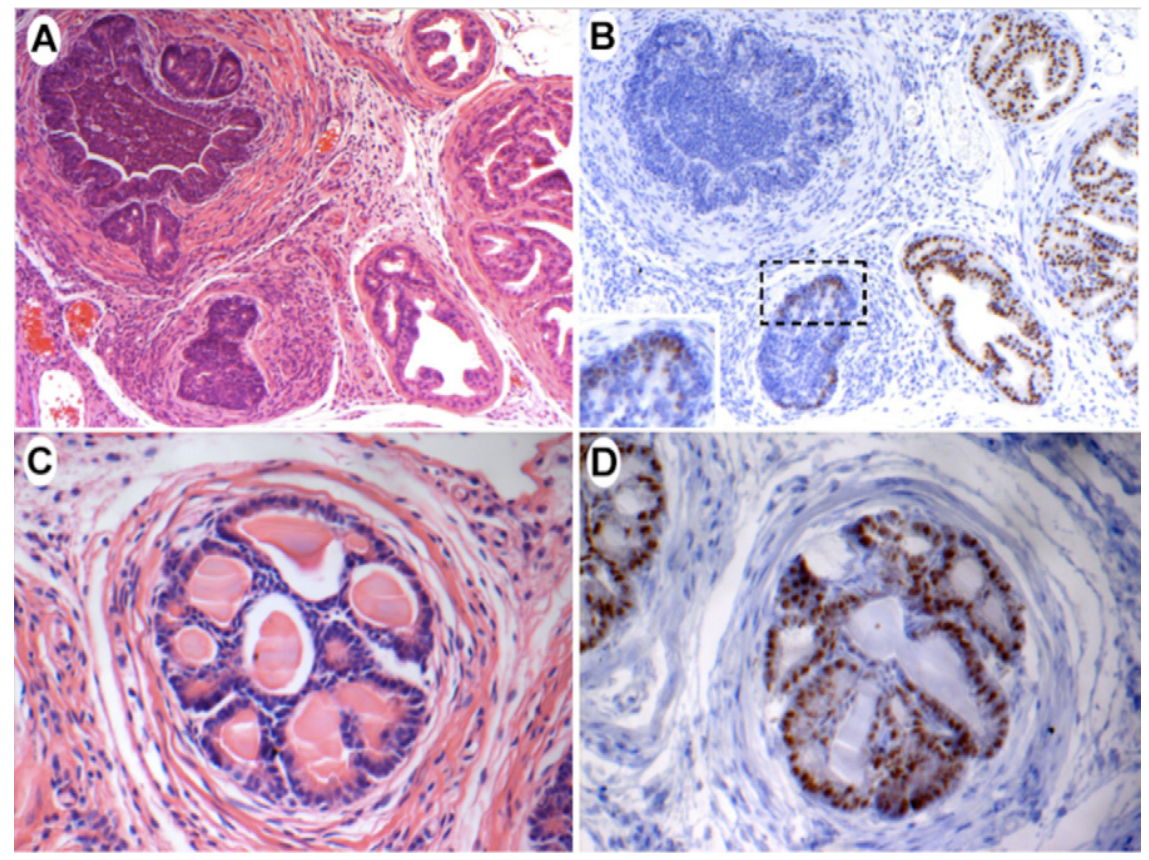

Figure 2. Nkx3.1 expression in CP9-infected anterior prostate. A: Day 14 anterior prostate. Note the juxtaposition of inflamed and noninflamed ducts. H\&E, $\times 100$. B: Section adjacent to that shown in $\mathbf{A}$, stained with anti-Nkx3.1 antibody. Note the marked reduction in Nkx3.1 staining from the inflamed duct, whereas noninflamed duct shows normal Nkx3.1 expression. Immunoperoxidase, $\times 100$. C: Day 14 anterior prostate. Note the absence of glandular infiltrate and the newly generated cribriform architecture. H\&E $\times 400$. D: Section adjacent to that shown in C, stained with anti-Nkx3.1 antibody. Nkx3.1 staining is almost uniformly restored, although it remains absent from a subset of epithelial cells closest to the lumen. Immunoperoxidase, $\times 400$

Increased fibrosis and angiogenesis was often seen in the stroma. At day 10, severe periglandular and stromal monocytic inflammation was frequently seen in certain areas of the dorsal lobe (Figure 1E). The ductal epithelium remained multilayered and hyperchromatic, with some ducts appearing atrophic. At day 14, the overall dorsal lobe morphology remained consistent with the morphology seen at day 10 (Figure 1F). In some ducts, the epithelial layer exhibited extensive disorganized stratification.

\section{Lateral Prostate}

The lateral prostate was the most consistently uninvolved lobe among CP9-inoculated mice. Despite having clear luminal spaces, the lateral lobe stroma often contained a mild infiltration of predominantly mononuclear inflammatory cells (Figure 1G). At later time points, the ductal epithelium appeared more contracted than normal with increased infoldings that were considered unusual for normal lateral ducts. Furthermore, the epithelial cells within condensed ducts exhibited a hyperchromatic columnar morphology (Figure 11). An inflammatory response within the lateral prostate was seen in only $10 \%$ of CP9-infected mice. The lateral lobe contained a mix of involved and uninvolved ducts with increased stromal thickening and a dense stromal monocytic infiltrate. Although the infected ducts contained luminal inflammatory cells, the density of the debris and neutrophils was much less than that observed in other lobes (Figure $1 \mathrm{H}$ ). The ductal epithelium was hyperchromatic and markedly multilayered, however it remained well organized.

\section{Ventral Prostate}

Although juxtaposed to the frequently uninvolved lateral lobe, ventral prostate inflammation was the most consis- tent finding among CP9-infected mice. At all time points, both lobes were severely inflamed and included virtually all ducts. At day 5, an acute inflammatory response comprising mainly luminal neutrophils was seen (Figure 1J). The stroma appeared thicker than normal and also contained a mild to moderate level of neutrophilic infiltration. Although multilayering was evident in the epithelium, the luminal cells maintained a lush cytoplasm with basally located nuclei. In certain affected ducts, the epithelium appeared atrophic with scant cytoplasm. At day 10, a moderately thickened interductal stroma was severely infiltrated with sheets of inflammatory monocytes (Figure $1 \mathrm{~K})$. The ducts remained multilayered with an intact hyperchromatic epithelium that exhibited a thinned cytoplasm. By day 14, the stromal infiltration was mainly monocytic and increased capillary formation was also observed (Figure 1L). The prostate ducts remained highly inflamed with neutrophils and occasionally pusfilled lumens. Multilayering within the ductal epithelium was still present, although a proportion of ducts appeared monolayered and had started regaining cytoplasmic volume.

\section{Diminished Nkx3.1 Protein Expression in the Inflamed Prostate}

Given the decrease in NKX3.1 protein expression levels observed in human PIA lesions as well as the possible role that Nkx3.1 protein loss plays in promoting oxidative stress, it was of interest to investigate the status of Nkx3.1 within an inflamed setting. Normally, Nkx3.1 is robustly expressed in prostate epithelial cells in all lobes. The intensity of Nkx3.1 staining was significantly and nearly uniformly reduced in the presence of glandular inflammation (Figure 2B). Reduced Nkx3.1 immunostaining was observed across all lobes and time points. Interestingly, noninflamed ducts juxtaposed to inflamed ducts showed 

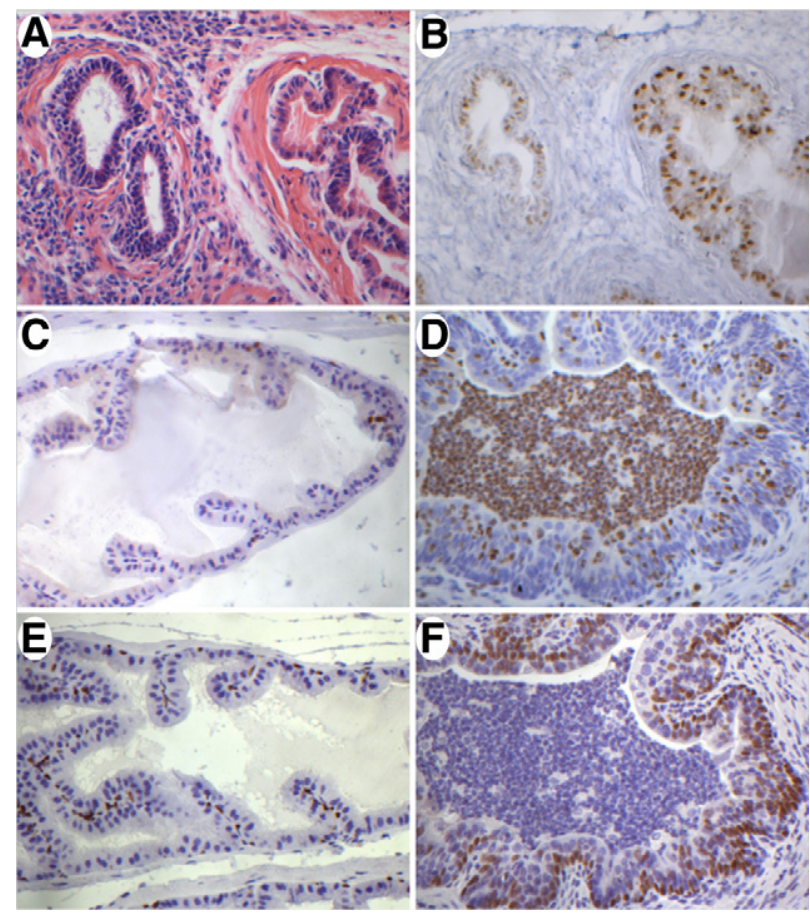

Figure 3. AR, Ki-67, and p63 expression in control and CP9-infected anterior prostate at day 14. A: Anterior prostate. Note the juxtaposition of an inflamed and noninflamed duct. B: Section adjacent to that shown in $\mathbf{A}$, stained with anti-AR antibody. Note the reduced AR staining from the inflamed duct. Noninflamed duct shows normal AR expression. C: Ki-67 immunostaining in control section from anterior prostate demonstrating a very low proliferative index in the normal prostate. D: Day 14 infected anterior prostate showing a marked increase in Ki-67 nuclear staining. E: Nuclear p63 immunostaining in the basal epithelial layer in normal prostate. Note the slender and slightly angular morphology of basal nuclei. F: Increased expression of p63 in a basally-located layer of cells lining the infected duct. Note the change in nuclear morphology from that seen in $\mathbf{E}$ and the appearance of scattered p63-positive cells closer to the lumen. H\&E $(\mathbf{A}) \times 400$. Immunoperoxidase (B-F) $\times 400$.

apparently normal Nkx3.1 expression (Figure 2, A and B). On clearance of inflammation, which presumably reflects clearance of infection, in certain anterior ducts at later time points, Nkx3.1 expression was restored (Figure 2, C and D). An interesting pattern of Nkx3.1 expression reminiscent of that reported in TRAMP PIN lesions was observed in the newly generated anterior ducts (Figure 2D). ${ }^{37}$ Epithelial cells closest to the stromal layer exhibited intense Nkx3.1 staining, whereas cells closer to the lumen had reduced or completely diminished Nkx3.1 protein levels.

\section{Androgen Receptor Expression Is Down-Regulated in Response to Inflammation}

Androgen receptor expression is normally expressed in the nuclei of both prostate epithelial and stromal cells in all four lobes. In response to inflammation, androgen receptor expression was down-regulated in infected ducts, although it remained detectable in all cases (Figure 3, A and B). Similar to Nkx3.1, AR expression was retained in noninflamed ducts juxtaposed adjacent to inflamed ducts. As the inflammation was cleared, AR expression was restored in prostate epithelial cells (data not shown).

\section{Inflamed Ducts Show an Increased Proliferative Index}

Immunostaining for Ki-67, a cell proliferation-associated marker, was performed to determine whether the inflammatory response associated with a reduction in Nkx3.1 expression allowed for an increase in cell proliferation. Normal prostate tissue has a very low Ki-67 index (Figure 3C). Inflamed ducts that exhibited epithelial hyperplasia showed a marked increase in Ki-67 staining when compared with normal epithelium (Figure 3D). Quantification of Ki-67 staining revealed a fivefold increase in inflamed ducts versus adjacent normal ducts (supplemental Figure 1 at http://ajp.amjpathol.org).

\section{Up-Regulation of p63 Expression in Infected Ducts}

In normal prostate epithelium, p63 is typically restricted to the basal compartment (Figure 3E). In PIA/atrophy, PIN, and prostate cancer, nuclear p63 expression becomes reduced as the basal layer becomes fragmented and lost. ${ }^{38}$ Interestingly, in CP9-infected mice, p63 was robustly expressed in a uniform basally-located layer of cells lining the entire inflamed ducts (Figure 3F). Furthermore, p63 expression was seen in a subset of scattered luminal epithelial cells (Figure 3F). An apparent change in basal nuclear morphology was also observed with p63 immunostaining. In normal prostate basal cells, nuclei are usually slender and occasionally angular in appearance (Figure 3E). In CP9-infected prostates, p63-expressing cells had more rounded-looking nuclei that were closely packed, in contrast to the well-spaced basal nuclei seen in normal prostate epithelium (Figure 3F). Consistent with the increase in p63-positive cells, immunostaining for Cytokeratin 5 (CK5) revealed expansion of CK5 immunoreactivity into the suprabasal layers (Supplemental Figure 2A at http://ajp.amjpathol.org). In some ducts the luminal cell layer, although negative for p63, was weakly to moderately positive for CK5 (Supplemental Figure 2A at http://ajp.amjpathol.org). These ducts, therefore, are similar to human focal atrophy/PIA lesions. ${ }^{15}$ However, in other ducts, a nearly intact layer of CK5 negative cells lining the lumen remained even in severely inflamed ducts (Supplemental Figure 2A at $h$ ttp://ajp.amjpathol.org). Importantly, Nkx3.1 and AR immunoreactivity was markedly reduced to nearly extinguished in these luminal cells, which typically have high expression levels of both proteins (Supplemental Figure 2, C and D, at http://ajp. amjpathol.org).

\section{Immunological and Histological Analysis of the Prostatic Infiltrate}

Overall, a typical inflammatory response to bacterial invasion was observed across the course of infection. At 


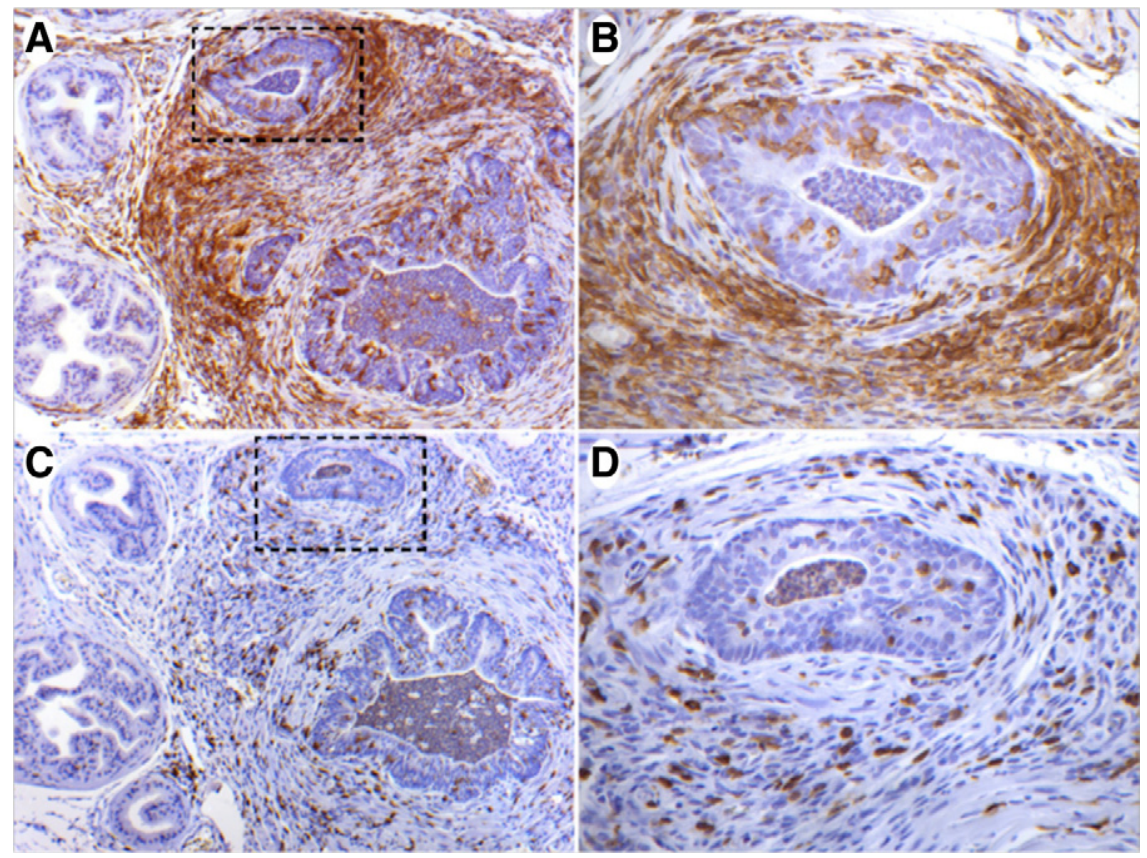

Figure 4. Immunohistochemical characterization of the inflammatory infiltrate in bacteriallyinduced prostatitis. A: Anterior prostate section from CP9-infected mice at day 14 stained with the macrophage marker F4/80. Note the dense stromal and periglandular macrophage infiltration. B: High-power image of boxed region indicated in A demonstrating intraepithelial macrophage infiltration. C: A nearby section to that shown in $\mathbf{A}$, stained with the T-cell marker CD3. D: High-power image of boxed region indicated in $\mathbf{C}$ demonstrating stromal and intraepithelial T-cell presence. Immunoperoxidase $(\mathbf{A}-\mathbf{D})$. Original magnifications: $\times 100(\mathbf{A}, \mathbf{C}), \times 400(\mathbf{B}, \mathbf{D})$.

day 5, the inflammatory response was predominantly neutrophil-based and located within the glandular lumens as well as the stroma. A small percentage of scattered mononuclear inflammatory cells were observed in the stroma. Although the neutrophilic glandular infiltrate persisted at day 10, there was a marked increase in periglandular and stromal infiltration by mononuclear inflammatory cells. By day 14, some glandular inflammatory constituents began taking the appearance of pus and the intensity of periglandular mononuclear inflammation increased dramatically (Figure 1, F and L). There was also a notable increase in the appearance of plasma cells at day 14.

Quantitative histopathological analysis of the inflammatory response revealed considerable variability among the prostate lobes. Box plots in Supplemental Figure 3 at http://ajp.amjpathol.org, show the distribution of inflammation type (acute versus chronic) in prostate lobes as a function of time from the CP9-infected and mock-infected animals. The ventral lobe showed the highest total acute and chronic inflammation score at all time points (Supplemental Figure 3 at http://ajp.amjpathol.org). In marked contrast, the lateral lobe was always the least affected and rarely showed evidence of either acute or chronic inflammatory infiltrate in any compartment. Within the ventral lobe, the distribution of inflammation by compartment is shown in Supplemental Figure 4 at http://ajp. amjpathol.org. The luminal compartment showed the highest extent of acute inflammation that persisted throughout the course of the experiment, whereas a canonical acuteto-chronic transition occurred in the stroma.

Immunohistochemical analysis of F4/80, a murine macrophage marker, revealed intense stromal and periglandular infiltration at day 14 (Figure 4A). Furthermore, F4/80 immunostaining demonstrated that a subset of macrophages had infiltrated the ductal epithelium and continued into the glandular lumen (Figure 4B). The prevalence of T-cells within the lymphocytic infiltrate was investigated by staining for the T-cell surface antigen CD3. A marked increase in CD3 + T-cells within the stroma and ductal intraepithelial regions was detected in inflamed regions at day 14 (Figure 4, C and D). These data support the progression of the classic inflammatory response that initiates with neutrophil recruitment, followed sequentially by macrophages, $T$ and B lymphocytes, and plasma cells.

\section{Discussion}

In 1863, the German physician Rudolph Virchow noted the consistent occurrence of leukocytes within neoplastic tissue and put forth the hypothesis that chronic inflammation could predispose a region to cellular proliferation and tumor formation. ${ }^{9}$ More than a century later, this connection was validated in a number of organs including the stomach, colon, and liver. ${ }^{39-43}$ The possibility that a similar scenario is taking place in the prostate has attracted considerable attention in the last decade. ${ }^{3,14,44}$ The occurrence of prostatitis-like symptoms accounts for $8 \%$ of urology office visits. ${ }^{45}$ Clinical prostatitis is the most commonly diagnosed prostate disorder in men under the age of 50 and the third most common, after benign prostatic hyperplasia and prostate cancer, in men older than $50 .{ }^{45}$ Although certain views point to a strong link between prostate inflammation and neoplastic transformation, others refute this connection. ${ }^{46-50}$ Virchow's original hypothesis and the discordant hypotheses in the field of prostate cancer provided the impetus to investigate the status of Nkx3.1, a key prostate tumor suppressor gene, in a mouse model of bacterial prostatitis.

Although prostatitis is a common clinical entity, the etiology underlying the majority of cases remains unclear. ${ }^{51}$ However, $5 \%$ to $10 \%$ of clinical prostatitis cases 
are confirmed to have a bacterial origin. ${ }^{52}$ The fact that more than $50 \%$ of chronic prostatitis patients experience alleviation of symptoms on administration of antibiotics has led to the speculation that a larger percentage of prostatitis cases are of microbial origin. ${ }^{53}$ In addition, several independent studies performed on prostatic tissue from cancer patients have detected bacterial $16 \mathrm{~S}$ rDNA sequences in $>85 \%$ of cases. ${ }^{54-56}$ These observations provided a strong rationale for using a bacterially-induced mouse model of prostatitis to attempt to establish a possible mechanism between prostate inflammation and carcinogenesis.

In a previous report, a bacterially-induced mouse model of prostatitis was developed, and a successful chronic inflammatory response was maintained within the prostate. ${ }^{18}$ Reactive epithelial hyperplasia associated with oxidative stress was linked to the chronic inflammatory state in infected mice. Although deemed useful for investigating a possible link between chronic inflammation and prostate cancer, concerns regarding the reproducibility of these results have been raised because of the preliminary status of this prostatitis model. ${ }^{57}$ In this report, we have independently and successfully reproduced bacterially-induced prostatitis in $\mathrm{C} 3 \mathrm{H} / \mathrm{HeOuJ}$ mice. The overall pattern of inflammation observed in our model in general paralleled the results previously reported by Elkahwaji et al. ${ }^{18}$ Our results have validated the mouse bacterial prostatitis model as a robust and reproducible system and further demonstrated that it is suitable for dissecting molecular pathways linking inflammation and cancer.

The current study addressed the status of Nkx3.1 expression in an inflamed setting using immunohistochemical analyses. Nkx3.1 staining was significantly diminished in virtually all inflamed prostatic ducts, a finding that was consistent across all four lobes and time points. The presence of intraluminal glandular infiltrate as opposed to periglandular or stromal inflammation appeared to govern Nkx3.1 expression status. Ducts devoid of glandular infiltrate in juxtaposition to inflamed ducts had apparently normal Nkx3.1 staining. At later time points, Nkx3.1 expression was restored in ducts that had cleared the lumen of inflammatory cells, providing further evidence for a link between glandular infiltrate and Nkx3.1 loss. Although the time course of our study was relatively short, signs of a chronic inflammatory response were evident after two weeks. Furthermore, the previous report by Elkahwaji et al ${ }^{18}$ confirmed a consistent chronic response 12 and 26 weeks postinoculation in this mouse prostatitis model. If $\mathrm{Nk} \times 3.1$ acts as a tumor suppressor and protects epithelial cells from oxidative stress and an inflamed setting results in a transient loss of Nkx3.1, it follows that down-regulation of this key prostate tumor suppressor might provide for an environment that allows for increased oxidative damage, cell proliferation, and neoplastic transformation. It is important to note that despite the presence of a profound glandular inflammatory cell infiltrate and significant expansion of the CK5/p63positive basal cell compartment, the luminal epithelial layer remained intact in most glands. Hence, it is unlikely that the severe diminution of Nkx3.1 and AR expression is attributable to elimination of the cell population that normally expresses these transcriptional regulators. Rather, like human focal atrophy/PIA we propose that many of these luminal cells are intermediate in their differentiated state between basal and luminal cells. Although not typically commented on, injured epithelium in human focal atrophy/PIA lesions often show a multilayered basal cell compartment as well (AM De Marzo, unpublished observations).

The mechanism by which Nkx3.1 is down-regulated in the context of an inflammatory setting has not been directly explored in this study. The fact that Nkx3.1 is an androgen-regulated gene and that $A R$ expression is down-regulated concomitantly in inflamed ducts could provide a partial mechanism by which Nkx3.1 expression is controlled. However, this warrants further investigation at the mRNA level. Preliminary results investigating the effects of pro-inflammatory cytokines including interleukin- $1 \beta$ and tumor necrosis factor $\alpha$ on Nkx3.1 expression could provide an alternative mechanism by which Nkx3.1 is down-regulated (CJB, unpublished results). When $\mathrm{LNCaP}$ prostate cancer cells, which express receptors for interleukin-1 $\beta$ and tumor necrosis factor $\alpha$, were cultured in the presence of physiological levels of either cytokine, a marked decrease in Nk×3.1 protein levels was observed. In inflamed ducts, neutrophilic production of proinflammatory cytokines may account for the decrease in Nkx3.1 expression in ductal epithelial cells. Furthermore, the fact that the clearance of the neutrophilic infiltrate restored $\mathrm{Nk} \times 3.1$ protein levels provides support for this regulatory mechanism.

We also observed an intriguing pattern for p63 expression in infected ducts. The majority of inflamed ducts exhibited a marked increase in cellularity and in the proliferation marker Ki-67. Robust nuclear p63 staining was detected in a basally-located and densely packed layer of cells lining the entire inflamed duct in contrast to the frequent p63 loss reported in some PIA lesions, some PIN lesions, and virtually all prostate adenocarcinoma lesions. Although p63 loss suggests a tumor suppressor role for this protein, complete loss of p63 in homozygous null mice results in a lack of prostate bud induction at birth, indicating a crucial role for p63 in prostate initiation and development. ${ }^{58}$ Furthermore, in the epidermis, p63 is required for initiation of epithelial stratification and for maintaining the proliferative potential in the mature epidermis. ${ }^{59}$ Indeed, a common feature we observed in inflamed prostate ducts was a high degree of stratification indicating a possible role for p63 in this phenotype. Our results suggest that p63 might play a dual tumor suppressor/growth stimulatory role in prostate development and tumorigenesis.

Prostate disease in humans exhibits a high degree of zonal preference. Both prostatitis and prostate cancer occur most commonly in the peripheral zone. Although Elkahwaji et al ${ }^{18}$ did not report preferential inflammatory localization, we observed a lobular preference of prostate inflammation. Whereas the ventral lobe was inflamed in $100 \%$ of CP9-infected animals, only $10 \%$ exhibited any inflammation in the lateral prostate. Both the anterior and dorsal prostate exhibited variable degrees of inflammation. 
Because the mouse strain used in both studies was consistent, the lobular preference we observed could be attributable to bacterial strain differences between the two studies. However, our findings provide support for the preferential occurrence of prostatitis in a regional manner.

In conclusion, the data reported here demonstrate that bacterially-induced prostate inflammation results in a profound concomitant loss of Nkx3.1 expression. This suggests that in the cognate human disease, lower Nkx3.1 levels may occur in a subset of bacterial prostatitis cases. Although a definitive epidemiological link between bacterial prostatitis and prostate cancer has not been established, the fact that expression of $\mathrm{Nk} \times 3.1$, a key tumor suppressor gene, is down-regulated in an inflammatory setting provides strong support for the link between prostate inflammation, oxidative stress and carcinogenesis.

\section{Acknowledgments}

We gratefully acknowledge Dr. Alison D. O'Brien for the kind gift of the CP9 uropathogenic E. coli strain and Gretchen Hubbard for assistance with statistical analyses.

\section{References}

1. Jemal A, Siegel R, Ward E, Murray T, Xu J, Thun MJ: Cancer statistics, 2007. CA Cancer J Clin 2007, 57:43-66

2. Sciavolino PJ, Abate-Shen C: Molecular biology of prostate development and prostate cancer. Ann Med 1998, 30:357-368

3. De Marzo AM, Platz EA, Sutcliffe S, Xu J, Gronberg H, Drake CG, Nakai $Y$, Isaacs WB, Nelson WG: Inflammation in prostate carcinogenesis. Nat Rev Cancer 2007, 7:256-269

4. Lee F, Torp-Pedersen ST, Siders DB, Littrup PJ, McLeary RD: Transrectal ultrasound in the diagnosis and staging of prostatic carcinoma. Radiology 1989, 170:609-615

5. McNeal JE: Cancer volume and site of origin of adenocarcinoma in the prostate: relationship to local and distant spread. Hum Pathol 1992, 23:258-266

6. Gonzalgo ML, Isaacs WB: Molecular pathways to prostate cancer. J Urol 2003, 170:2444-2452

7. Chin JL, Reiter RE: Genetic alterations in prostate cancer. Curr Urol Rep 2004, 5:157-165

8. Abate-Shen C, Shen MM: Molecular genetics of prostate cancer. Genes Dev 2000, 14:2410-2434

9. Balkwill F, Mantovani A: Inflammation and cancer: back to Virchow? Lancet 2001, 357:539-545

10. Federico A, Morgillo F, Tuccillo C, Ciardiello F, Loguercio C: Chronic inflammation and oxidative stress in human carcinogenesis. Int $J$ Cancer 2007, 121:2381-2386

11. Kawanishi S, Hiraku Y, Pinlaor S, Ma N: Oxidative and nitrative DNA damage in animals and patients with inflammatory diseases in relation to inflammation-related carcinogenesis. Biol Chem 2006, 387:365-372

12. McNeal JE: Normal histology of the prostate. Am J Surg Pathol 1988, 12:619-633

13. Franks LM: Atrophy and hyperplasia in the prostate proper. J Pathol Bacteriol 1954, 68:617-621

14. De Marzo AM, Marchi VL, Epstein JI, Nelson WG: Proliferative inflammatory atrophy of the prostate: implications for prostatic carcinogenesis. Am J Pathol 1999, 155:1985-1992

15. van Leenders GJ, Gage WR, Hicks JL, van Balken B, Aalders TW, Schalken JA, De Marzo AM: Intermediate cells in human prostate epithelium are enriched in proliferative inflammatory atrophy. Am J Pathol 2003, 162:1529-1537

16. Gurel B, Iwata T, Koh CM, Jenkins RB, Lan F, Van Dang C, Hicks JL, Morgan J, Cornish TC, Sutcliffe S, Isaacs WB, Luo J, De Marzo AM:
Nuclear MYC protein overexpression is an early alteration in human prostate carcinogenesis. Mod Pathol 2008, 21:1156-1167

17. Bushman W: Edited by Lepor H. Philadelphia, W.B. Saunders Company, 2000, pp. 550-557

18. Elkahwaji JE, Zhong W, Hopkins WJ, Bushman W: Chronic bacterial infection and inflammation incite reactive hyperplasia in a mouse model of chronic prostatitis. Prostate 2007, 67:14-21

19. Bieberich CJ, Fujita K, He WW, Jay G: Prostate-specific and androgen-dependent expression of a novel homeobox gene. J Biol Chem 1996, 271:31779-31782

20. Sciavolino PJ, Abrams EW, Yang L, Austenberg LP, Shen MM, AbateShen C: Tissue-specific expression of murine Nkx3.1 in the male urogenital system. Dev Dyn 1997, 209:127-138

21. Bhatia-Gaur R, Donjacour AA, Sciavolino PJ, Kim M, Desai N, Young P, Norton CR, Gridley T, Cardiff RD, Cunha GR, Abate-Shen C, Shen MM: Roles for Nk×3.1 in prostate development and cancer. Genes Dev 1999, 13:966-977

22. Schneider A, Brand T, Zweigerdt R, Arnold H: Targeted disruption of the Nkx3.1 gene in mice results in morphogenetic defects of minor salivary glands: parallels to glandular duct morphogenesis in prostate. Mech Dev 2000, 95:163-174

23. Tanaka M, Komuro I, Inagaki H, Jenkins NA, Copeland NG, Izumo S: Nkx3.1, a murine homolog of Drosophila bagpipe, regulates epithelial ductal branching and proliferation of the prostate and palatine glands. Dev Dyn 2000, 219:248-260

24. Bowen C, Bubendorf L, Voeller HJ, Slack R, Willi N, Sauter G, Gasser TC, Koivisto P, Lack EE, Kononen J, Kallioniemi OP, Gelmann EP: Loss of NKX3.1 expression in human prostate cancers correlates with tumor progression. Cancer Res 2000, 60:6111-6115

25. Asatiani E, Huang WX, Wang A, Rodriguez Ortner E, Cavalli LR, Haddad BR, Gelmann EP: Deletion, methylation, and expression of the NKX3.1 suppressor gene in primary human prostate cancer. Cancer Res 2005, 65:1164-1173

26. He WW, Sciavolino PJ, Wing J, Augustus M, Hudson P, Meissner PS, Curtis RT, Shell BK, Bostwick DG, Tindall DJ, Gelmann EP, AbateShen C, Carter KC: A novel human prostate-specific, androgenregulated homeobox gene (NKX3.1) that maps to 8p21, a region frequently deleted in prostate cancer. Genomics 1997, 43:69-77

27. Ouyang X, DeWeese TL, Nelson WG, Abate-Shen C: Loss-of-function of Nkx3.1 promotes increased oxidative damage in prostate carcinogenesis. Cancer Res 2005, 65:6773-6779

28. Bethel CR, Faith D, Li X, Guan B, Hicks JL, Lan F, Jenkins RB, Bieberich CJ, De Marzo AM: Decreased NKX3.1 protein expression in focal prostatic atrophy, prostatic intraepithelial neoplasia, and adenocarcinoma: association with gleason score and chromosome 8p deletion. Cancer Res 2006, 66:10683-10690

29. Russo TA, Guenther JE, Wenderoth S, Frank MM: Generation of isogenic K54 capsule-deficient Escherichia coli strains through TnphoA-mediated gene disruption. Mol Microbiol 1993, 9:357-364

30. Russo TA, Davidson BA, Genagon SA, Warholic NM, Macdonald U, Pawlicki PD, Beanan JM, Olson R, Holm BA, Knight PR 3rd: E. coli virulence factor hemolysin induces neutrophil apoptosis and necrosis/lysis in vitro and necrosis/lysis and lung injury in a rat pneumonia model. Am J Physiol Lung Cell Mol Physiol 2005, 289:L207-L216

31. Rippere-Lampe KE, O'Brien AD, Conran R, Lockman HA: Mutation of the gene encoding cytotoxic necrotizing factor type $1(\operatorname{cnf}(1))$ attenuates the virulence of uropathogenic Escherichia coli. Infect Immun 2001, 69:3954-3964

32. Smith YC, Grande KK, Rasmussen SB, O'Brien AD: Novel threedimensional organoid model for evaluation of the interaction of uropathogenic Escherichia coli with terminally differentiated human urothelial cells. Infect Immun 2006, 74:750-757

33. Chen H, Bieberich CJ: Structural and functional analysis of domains mediating interaction between NKX-3.1 and PDEF. J Cell Biochem 2005, 94:168-177

34. Rippere-Lampe KE, Lang M, Ceri H, Olson M, Lockman HA, O'Brien AD: Cytotoxic necrotizing factor type 1-positive Escherichia coli causes increased inflammation and tissue damage to the prostate in a rat prostatitis model. Infect Immun 2001, 69:6515-6519

35. Andreu A, Stapleton AE, Fennell C, Lockman HA, Xercavins M, Fernandez F, Stamm WE: Urovirulence determinants in Escherichia coli strains causing prostatitis. J Infect Dis 1997, 176:464-469

36. Mitsumori K, Terai A, Yamamoto S, Ishitoya S, Yoshida O: Virulence 
characteristics of Escherichia coli in acute bacterial prostatitis. J Infect Dis 1999, 180:1378-1381

37. Bethel CR, Bieberich CJ: Loss of Nkx3.1 expression in the transgenic adenocarcinoma of mouse prostate model. Prostate 2007, 67:17401750

38. Parsons JK, Gage WR, Nelson WG, De Marzo AM: p63 protein expression is rare in prostate adenocarcinoma: implications for cancer diagnosis and carcinogenesis. Urology 2001, 58:619-624

39. Blaser MJ, Chyou PH, Nomura A: Age at establishment of Helicobacter pylori infection and gastric carcinoma, gastric ulcer, and duodenal ulcer risk. Cancer Res 1995, 55:562-565

40. Caselmann WH, Alt M: Hepatitis $\mathrm{C}$ virus infection as a major risk factor for hepatocellular carcinoma. J Hepatol 1996, 24:61-66

41. Cromlish JA: Hepatitis B virus-induced hepatocellular carcinoma: possible roles for HBx. Trends Microbiol 1996, 4:270-274

42. Guidotti LG, Chisari FV: Immunobiology and pathogenesis of viral hepatitis. Annu Rev Pathol 2006, 1:23-61

43. Levin B: Ulcerative colitis and colon cancer: biology and surveillance. J Cell Biochem Suppl 1992, 16G:47-50

44. Lucia MS, Torkko KC: Inflammation as a target for prostate cancer chemoprevention: pathological and laboratory rationale, J Urol 2004, 171:S30-34; discussion S35

45. Collins MM, Stafford RS, O'Leary MP, Barry MJ: How common is prostatitis? A national survey of physician visits. J Urol 1998, 159:1224-1228

46. Nelson WG, De Marzo AM, Isaacs WB: Prostate cancer. N Engl J Med 2003, 349:366-381

47. Palapattu GS, Sutcliffe S, Bastian PJ, Platz EA, De Marzo AM, Isaacs WB, Nelson WG: Prostate carcinogenesis and inflammation: emerging insights. Carcinogenesis 2005, 26:1170-1181

48. Postma R, Schroder FH, van der Kwast TH: Atrophy in prostate needle biopsy cores and its relationship to prostate cancer incidence in screened men. Urology 2005, 65:745-749

49. Anton RC, Kattan MW, Chakraborty S, Wheeler TM: Postatrophic hyperplasia of the prostate: lack of association with prostate cancer. Am J Surg Pathol 1999, 23:932-936

50. Sciarra A, Di Silverio F, Salciccia S, Autran Gomez AM, Gentilucci A Gentile V: Inflammation and chronic prostatic diseases: evidence for a link? Eur Urol 2007, 52:964-972

51. Karlovsky ME, Pontari MA: Theories of prostatitis etiology. Curr 2002, 307-312

52. Gurunadha Rao Tunuguntla HS, Evans CP: Management of prostatitis. Prostate Cancer Prostatic Dis 2002, 5:172-179

53. Nickel JC, Downey J, Johnston B, Clark J: Predictors of patient response to antibiotic therapy for the chronic prostatitis/chronic pelvic pain syndrome: a prospective multicenter clinical trial. J Urol 2001, 165:1539-1544

54. Sfanos KS, Sauvageot J, Fedor HL, Dick JD, De Marzo AM, Isaacs WB: A molecular analysis of prokaryotic and viral DNA sequences in prostate tissue from patients with prostate cancer indicates the presence of multiple and diverse microorganisms. Prostate 2008, 68:306-320

55. Hochreiter WW, Duncan JL, Schaeffer AJ: Evaluation of the bacterial flora of the prostate using a 16S rRNA gene based polymerase chain reaction. J Urol 2000, 163:127-130

56. Keay S, Zhang CO, Baldwin BR, Alexander RB: Polymerase chain reaction amplification of bacterial 16s rRNA genes in prostate biopsies from men without chronic prostatitis. Urology 1999, 53:487-491

57. Vykhovanets EV, Resnick MI, MacLennan GT, Gupta S: Experimental rodent models of prostatitis: limitations and potential. Prostate Cancer Prostatic Dis 2007, 10:15-29

58. Signoretti S, Waltregny D, Dilks J, Isaac B, Lin D, Garraway L, Yang A, Montironi R, McKeon F, Loda M: p63 is a prostate basal cell marker and is required for prostate development. Am J Pathol 2000, 157: 1769-1775

59. Koster MI, Kim S, Mills AA, DeMayo FJ, Roop DR: p63 is the molecular switch for initiation of an epithelial stratification program. Genes Dev 2004, 18:126-131 